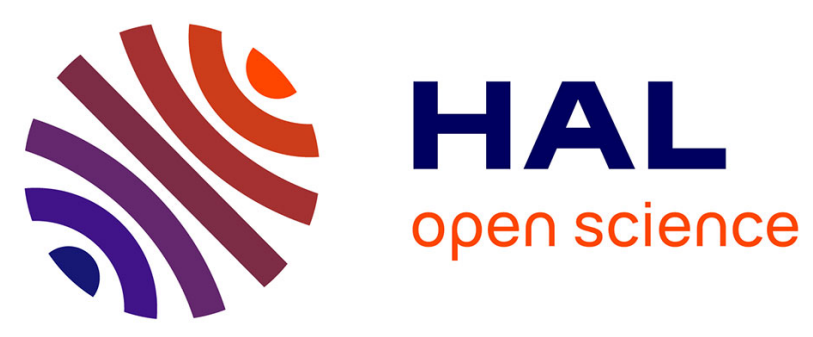

\title{
Comparison between centralized and decentralized storage energy management for Direct Wave Energy Converter Farm
}

Thibaut Kovaltchouk, Anne Blavette, Hamid Ben Ahmed, Bernard Multon, Judicael Aubry

\section{To cite this version:}

Thibaut Kovaltchouk, Anne Blavette, Hamid Ben Ahmed, Bernard Multon, Judicael Aubry. Comparison between centralized and decentralized storage energy management for Direct Wave Energy Converter Farm. Ecological Vehicles and Renewable Energies (EVER), 2015 Tenth International Conference on, Mar 2015, Monte-Carlo, Monaco. 10.1109/EVER.2015.7112985 . hal-01160252

\section{HAL Id: hal-01160252 \\ https://hal.science/hal-01160252}

Submitted on 5 Jun 2015

HAL is a multi-disciplinary open access archive for the deposit and dissemination of scientific research documents, whether they are published or not. The documents may come from teaching and research institutions in France or abroad, or from public or private research centers.
L'archive ouverte pluridisciplinaire $\mathbf{H A L}$, est destinée au dépôt et à la diffusion de documents scientifiques de niveau recherche, publiés ou non, émanant des établissements d'enseignement et de recherche français ou étrangers, des laboratoires publics ou privés. 


\section{Comparison between Centralized and Decentralized Storage Energy Management for Direct Wave Energy Converter Farm}

\author{
Thibaut Kovaltchouk, Anne Blavette, \\ Hamid Ben Ahmed, Bernard Multon \\ SATIE CNRS UMR8029 \\ ENS Rennes, UEB \\ Bruz, France \\ thibaut.kovaltchouk@ens-rennes.fr
}

\author{
Judicaël Aubry \\ Energy and Embedded systems for transportation \\ ESTACA'Lab \\ Laval, France
}

\begin{abstract}
This article compares the sizes of an Energy Storage System (ESS) with two control types in order to smooth a Direct Wave Energy Converter (DWEC) Farm Production, namely a centralized one that deals with the PCC power and a decentralized one that deals with each unit power production. The main objective is to compare the two controls on the basis of their life cycle cost. The SEAREV project is the Direct Wave Energy Converter used as an example in this paper. The ESS is necessary for grid integration in the case considered here due to the flicker constraint, which is not being satisfied without storage. The optimization strategies for both the sizing and the management of an Energy Storage System (ESS) will be described: the rule-based energy management approach depends on the State of Energy of this ESS as well as the power produced by the DWEC unit or the DWEC farm. This management strategy has been optimized for each size in order to reduce aging speed while strictly respecting the flicker criterion. The final design is expected to minimize total system cost. The centralized control clearly allowed smaller capacity, but has some drawbacks for the losses in the rest of the farm.
\end{abstract}

Keywords-Electrical Energy Storage System, Supercapacitors, Life Cycle Cost, Aging, Design optimization, Life Estimation, Power Smoothing, , Direct Wave Energy Converter, Grid Integration, Power Quality, Flicker.

(C) 2015 IEEE. Personal use of this material is permitted. Permission from IEEE must be obtained for all other uses, including reprinting/republishing this material for advertising or promotional purposes, collecting new collected works for resale or redistribution to servers or lists, or reuse of any copyrighted component of this work in other works

Kovaltchouk, Thibaut; Blavette, Anne; Ben Ahmed, Hamid; Multon, Bernard; Aubry, Judicael, "Comparison between centralized and decentralized storage energy management for Direct Wave Energy Converter Farm," Ecological Vehicles and Renewable Energies (EVER), 2015 Tenth International Conference on, pp.1,8, March 31 2015-April 22015

DOI: 10.1109/EVER.2015.7112985

\section{INTRODUCTION}

Grid integration of some renewables (e.g. wave energy) is a major challenge. In particular, the large power fluctuations generated by wave energy converters may impact power quality significantly. This impact is all the more important regarding Direct Wave Energy Converters (DWEC) for which the wave power fluctuations are not smoothed in the energy conversion chain.

In particular, flicker, a power quality criteria, has been identified as an important constraint for wave energy [1], [2], [3]. Indeed, the combination of the weak grid (which can be the case with a near-shore distribution grid) and fluctuations in production can cause significant flicker non-compliance. Smoothing the production with an Energy Storage System (ESS) is one way to solve this grid integration problem. The wave energy converter considered in this study is the SEAREV (see Fig. 1).

Many storage technologies have been investigated in order to smooth wave energy production; supercapacitors[4], flywheels [5] or Superconducting Magnetic Energy Storage (SMES) [6]. But few studies justify technically and economically the need of an energy storage system for Wave farm grid integration and quantify the impact of such systems on the energy cost. The purpose of this study therefore is to minimize the ESS cost while ensuring the power quality constraint to be satisfied (Fig. 1).

Life cycle cost analyses have rarely been included in the sizing process [7][8]. The life cycle analysis conducted for this problem with a decentralized control under similar hypotheses has already been presented in [9]. Centralized or coordinated control can have a great impact on the need of storage capacity, as will be seen 


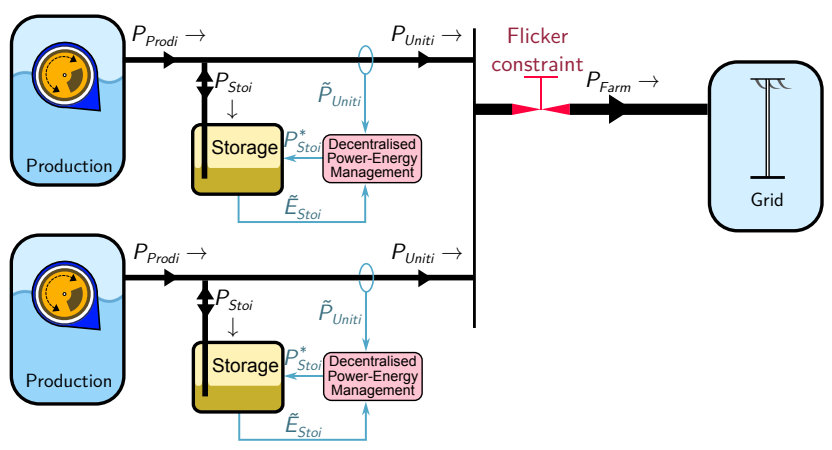

(a)

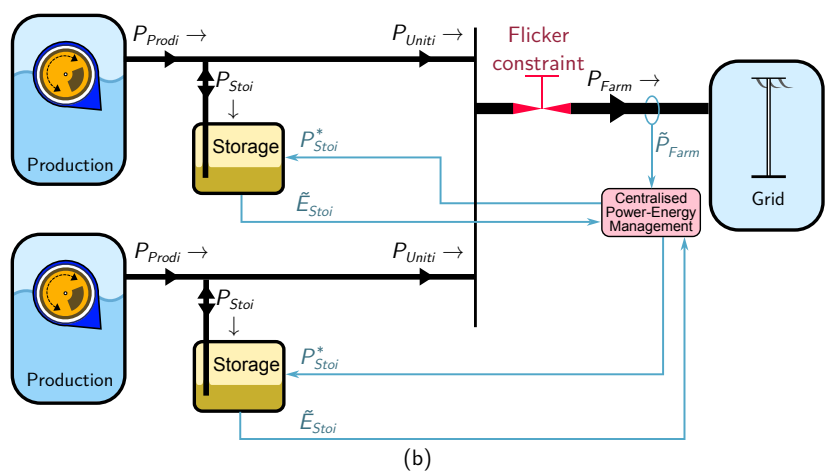

Fig. 1. Smoothing the power produced by a Wave Energy Converter farm thanks to on-board Energy Storage Systems for the purpose of satisfying a flicker constraint: Decentralized (a) vs. centralized (b) control

in this article.

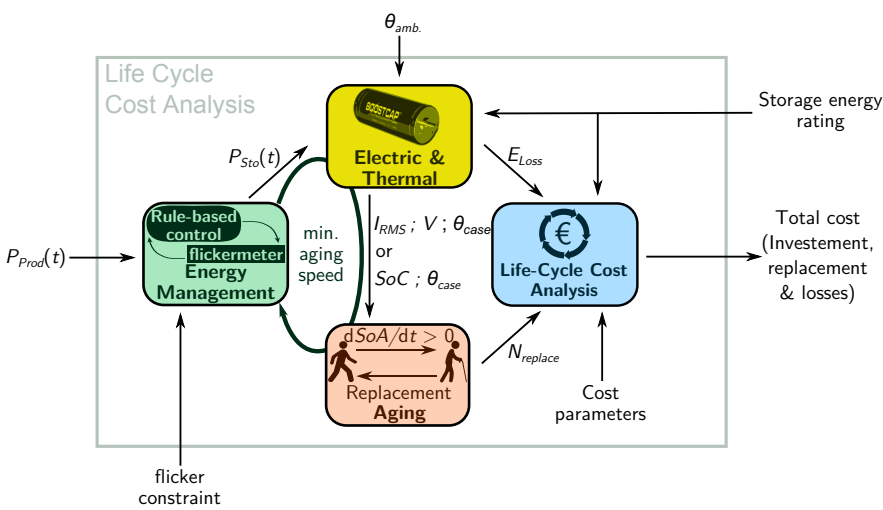

Fig. 2. Life cycle cost analysis applied to storage capacity sizing using electric, thermal and aging models with an optimized management strategy

Other centralized controls have been investigated for wind farms in order to participate in frequency regulation [10] [11]. Another study [12] proposed a coordinated control of a wave farm in order to maximize energy conversion. But, in all these cases, no Energy Storage Systems (ESS) are considered.

\section{MODELS AND HYPOTHESES}

\section{A. Rule-based Energy Management}

The complete system with all its power flows is illustrated in Figure 1.

The effects of losses on the dynamic behavior of the system are not significant, and so are neglected. With this assumption, the ESS is considered as a pure integrator. This assumption is often used for this type of problems, and can be summarized by the following equations:

$$
\begin{gathered}
\frac{d E_{\text {Sto } i}}{d t} \\
P_{\text {Sto } i}(t)=P_{\text {Sto } i}(t) \\
=P_{\text {Prod } i}(t)-P_{\text {Unit } i}(t)
\end{gathered}
$$

with $E_{S t o} i$ and $P_{S t o} i$, respectively, the stored energy and the power in the ESS of the unit $i, P_{P r o d} i$ the power produced by the DWEC $i$, and $P_{\text {Unit } i}$ the power injected into the substation by the unit $i$.

The decentralized energy management is a rule-based control strategy [13]:

$P_{\text {Sto } i}(t)=\alpha\left(P_{\text {Prod } i}(t)-P_{\text {Min }}\right)-\frac{E_{\text {Sto } i}(t)-E_{\text {Min }}}{\tau}$

With $P_{\text {Min }}$ the minimum value of the power produced by one unit of production (0 MW in our case).

Three adjustment parameters are found in this management rule, i.e.: $E_{M i n}, \tau$ and $\alpha$, which respectively denote the minimum stored energy, the storage time constant, and a ratio (bounded between 0 and 1) that is proportional to the share of smooth power within the power injected into the substation. These parameters can be adjusted for optimizing objectives and respect constraints. The management rule is illustrated in Figure 3.

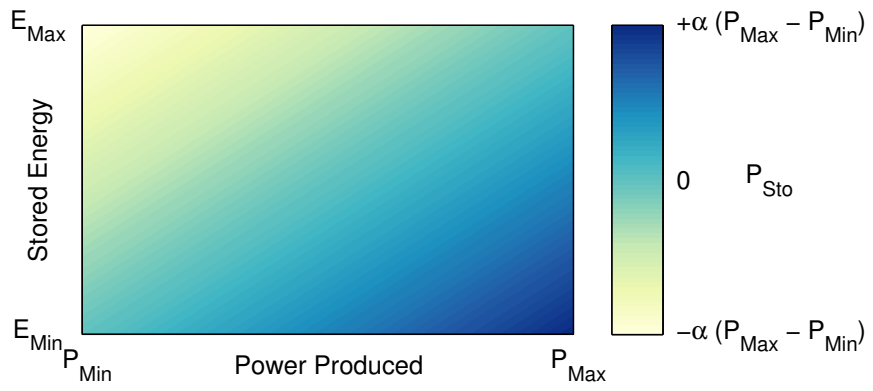

Fig. 3. Rule-based management strategy: stored power vs. the power produced (by one Wave Energy Converter for decentralized control or the whole farm for centralized control) and the ESS State of Energy (individual or equivalent). $\alpha$ is a parameter bounded between 0 and 1. 
The centralized energy management is the same rulebased control strategy, but with each ESS considered as $N$ identical parts of an equivalent bigger ESS:

$$
\begin{aligned}
P_{\text {Sto } i}(t)= & \alpha_{C} \frac{1}{N} \sum_{i=1}^{N}\left(P_{\text {Prod } i}(t)-P_{\text {Min }}\right) \\
& -\frac{1}{N} \sum_{i=1}^{N} \frac{E_{\text {Sto } i}(t)-E_{M i n C}}{\tau_{C}}
\end{aligned}
$$

In this case, the energies stored and the powers in each ESS are identical that is the best solution to reduce globally the losses and the aging in the ESS (because they are convex functions). This is illustrated in Fig. 4.

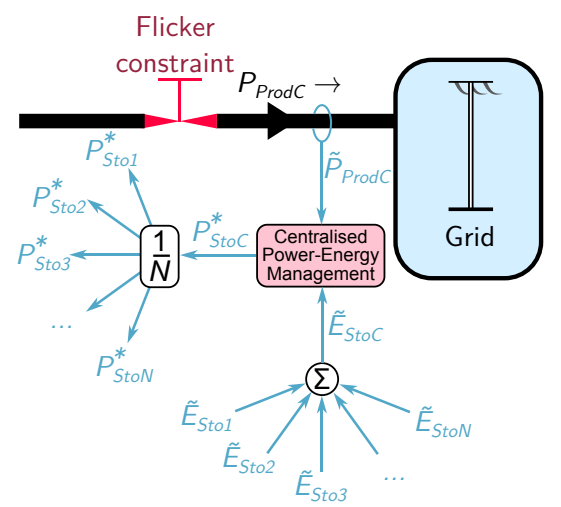

Fig. 4. Centralized management: the Energy Storage Systems are controlled like a big equivalent Energy Storage System with each Storage having the same state

\section{B. Flicker Definition and Standards}

To enable grid integration, energy producers must meet some constraints on the power quality. The limitation of voltage fluctuations (in particular flicker) is a critical constraint for WECs.

Flicker is a visible and objective change in brightness of a light source due to rapid fluctuations in the power supply voltage. These fluctuations are caused by variations in either active or reactive power to the network [14]. Beyond a certain amplitude, these rapid fluctuations (in a range from $5 \mathrm{mHz}$ to $33 \mathrm{~Hz}$ ) may cause humans to suffer from fatigue, irritability, cause epileptic seizures, but can also cause premature aging of electrical devices [15]. So these fluctuations are constrained by flicker standards to keep them limited (see Fig. 5).

Two flicker severity indexes are typically used in grid codes:

- The short-term flicker severity index $P_{s t}$ is measured over a 10-minute period,

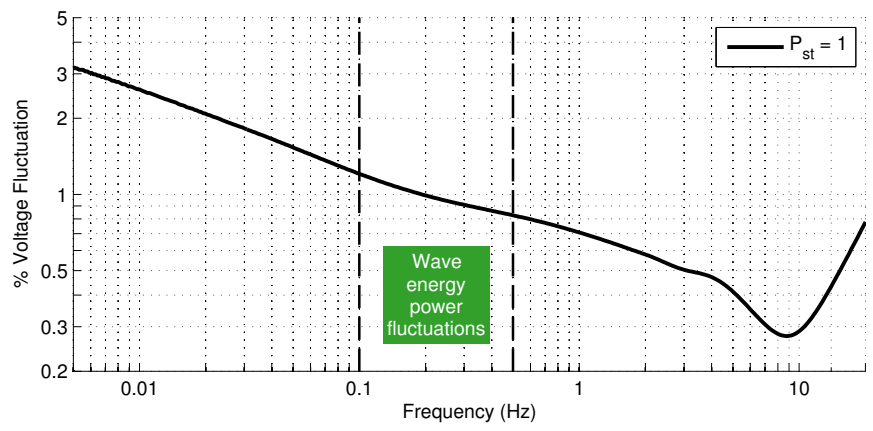

Fig. 5. Flicker constraint: $P_{s t}=1$ curve for regular rectangular voltage changes according to the IEC 61000-4-15 Standard. The zone above the curve corresponds to visual irritation for the customer. Wave power fluctuations of interest for electromechanical energy conversion typically fall between 0.1 and $0.5 \mathrm{~Hz}$.

- The long-term flicker severity index $P_{l t}$ is measured over 2 hours.

The long-term flicker severity index $P_{l t}$ is calculated with twelve consecutive values of the short term flicker severity index $P_{s t i}$ :

$$
P_{l t}=\left(\frac{1}{12} \sum_{i=1}^{12} P_{s t i}^{3}\right)^{1 / 3}
$$

Flicker measurement with a flickermeter is defined in the IEC 61000-4-15 Standard [14]. A flickermeter installed in Matlab is used [16]. Further details on the use of this flickermeter can be found in [13].

We make the hypothesis that the flicker severity index, for the frequency range considered here, is proportional to the standard deviation of the power produced and that the distance between the units is sufficiently great to consider that their individual power production is independent from one another. Thanks to the Bienaymé's formula, we found that $P_{l t}=\sqrt{N} \times P_{l t i}$ with $P_{l t}$, the total long-term flicker severity index for the farm, and $P_{l t i}$, the individual flicker severity index for each unit. Similar hypothesis are used for wind farms [17].

The Energy Storage System is necessary to satisfy the flicker constraint for some powerful sea-states and for the grid considered here (apparent short-circuit power of $50 \mathrm{MVA}$ and grid angle of $60^{\circ}$ ). The maximum longterm flicker severity index $P_{l t}$ for a wave farm is 0.25 , according to French rules [18] for a MV grid (distribution Medium-Voltage grid between $1 \mathrm{kV}$ and $50 \mathrm{kV}$, typically $20 \mathrm{kV}$ ). It is important to note that the French grid code is one of the most severe grid codes regarding flicker requirements [3]. 


\section{The Electrical and Thermal Models for the Storage System}

The Electrical Energy Storage System studied here consist of a Supercapacitor Banks. The electrical model chosen to model a supercapacitor is the connection of a capacitance $C$ and a resistance $E S R$ (Equivalent Series Resistance). This simple model is considered as valid in the case where the State-of-Energy is relatively constant. The validity of this hypothesis will be confirmed by the results.

A reference element is used: a Maxwell cell with a 3,000 Farads capacitance and a 2.7 volts rated voltage [19]. The series and parallel connections of these elements allow adjusting the rated voltage and the energy capacity of the ESS. All cells are assumed to be identical and to endure the same stresses. We can notice that balancing circuits are typically used to compensate voltage deviation between the cells, and thus help to make this assumption.

The self-heating effect is very important because the degradation rate accelerates exponentially with respect to temperature, as we will see later. The thermal time constant of the cells (around 2000 s [19]) are considered to be high enough relative to the waves period (typically ten seconds) so as to neglect case temperature variations. In order to determine the case temperature of the elements, we thus introduce a simple static thermal model:

$$
\theta_{c}=\theta_{a}+R_{\text {thca }} \overline{E S R \times I(t)^{2}}
$$

where $\theta_{c}$ and $\theta_{a}$ are the case and the ambient temperatures (the latter is assumed to be constant and equal to $\left.25^{\circ} \mathrm{C}\right), R_{\text {thca }}$ the thermal resistance of the element, and $I$ the current flowing through the component. The operator $\bar{x}$ represents the average of a quantity over a cycle duration (here one hour). Thus, during a cycle, the case temperature $\theta_{c}$ is considered as a constant. The thermal resistance $R_{\text {thca }}$ is $3.2 \mathrm{~K} / \mathrm{W}$.

\section{Supercapacitor Aging Models}

A state variable $S o A$ serves to quantify the Stateof-Aging; it is similar to the State-of-Health parameter found in some battery models [20]. The value is initially 0 and reaches 1 at the end of the device lifetime.

The supercapacitor aging model has been fully described in [9]. Aging speed depends on: the case temperature $\theta_{c}$, voltage across the cell $V$, and the root mean square current though the cell $I_{R M S}$ :

$$
\begin{aligned}
\frac{d S o A}{d t}=\frac{1}{T_{\text {life }}^{r e f}} & \times \exp \left(\frac{\theta_{c}-\theta_{c}^{r e f}}{\theta_{0}}\right) \\
\times & {\left[\exp \left(\frac{V-V^{r e f}}{V_{0}}\right)+K\right] } \\
\times & \exp \left(k_{R M S} \frac{I_{R M S}}{C}\right)
\end{aligned}
$$

where $T_{\text {life }}^{r e f}, \theta_{0}, \theta_{c}^{r e f}, V_{0}, V^{r e f}, K$ and $k_{R M S}$ are aging parameters found in [9] and given in Table I. $\tau_{\text {filter }} R M S$ corresponds to the time constant used to compute the RMS-current $I_{R M S}$.

TABLE I. PARAMETERS OF THE SUPERCAPACITORS AGING MODEL

\begin{tabular}{|c|c|}
\hline$\theta_{0}$ & $11 \mathrm{~K}$ \\
\hline$V_{0}$ & $130 \mathrm{mV}$ \\
\hline$K$ & $29 \times 10^{-3}$ \\
\hline$T_{\text {life }}^{r e f}$ & $1470 \mathrm{~h}$ \\
\hline$V^{\text {ref }}$ & $2.7 \mathrm{~V}$ \\
\hline$\theta^{\text {ref }}$ & $65^{\circ} \mathrm{C}$ \\
\hline$k_{R M S}$ & $68 \mathrm{~s} . \mathrm{V}^{-1}$ \\
\hline$\tau_{\text {filter } R M S}$ & $45 \mathrm{~s}$ \\
\hline
\end{tabular}

\section{E. Management Optimization}

During the sizing procedure, the management parameters $E_{M i n}, \tau$ and $\alpha$ are chosen to respect the flicker constraint while minimizing the average speed of aging for each capacity considered.

We can see an example of time-series obtained for the two control strategies for the same unit in Fig. 6: the power and the energy variation are much smaller with a centralized control. A more smaller capacity for the storage seems to be necessary to allow grid integration in this case, but with a more polluted production of each unit.

We can use an analogy to explain this result, illustrated by the figure 7: a listener surrounded by speakers. The speakers in the crowd represent noise production units, in similar fashion to wave energy converters which can be considered as producing power fluctuations from a grid point of view. The listener perceives the noise generated by all the speakers, in similar fashion to the grid which receives all the power fluctuations generated by the wave energy converters, thus resulting in flicker. In order to protect himself from excessive noise, the listener uses anti-noise panels. From a grid perspective, this corresponds to using energy storage systems intended to smooth the incoming power fluctuations, thus reducing the level of flicker 

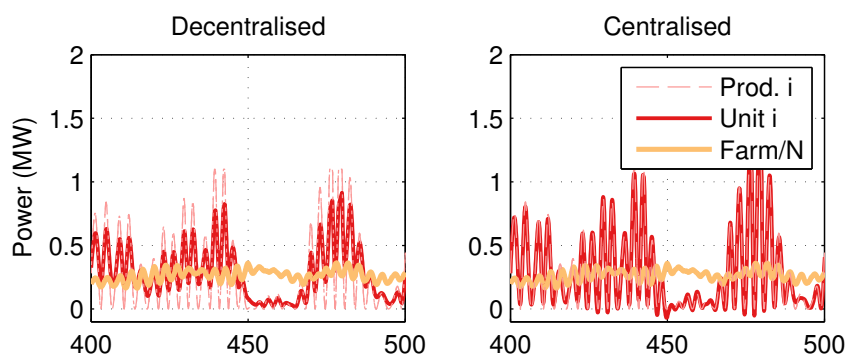

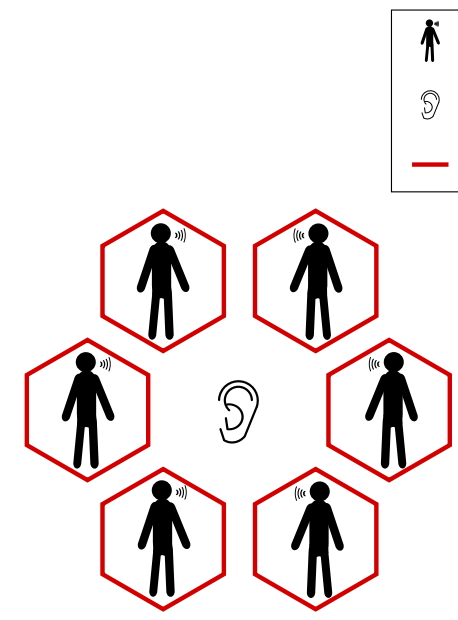

(a)
Speaker (generates noise)

Unit of production (generates flicker)

Ear (perceived noise) /

Grid (perceived flicker)

Anti-noise panels (reduce noise)/

Energy Storage Systems (reduce flicker)
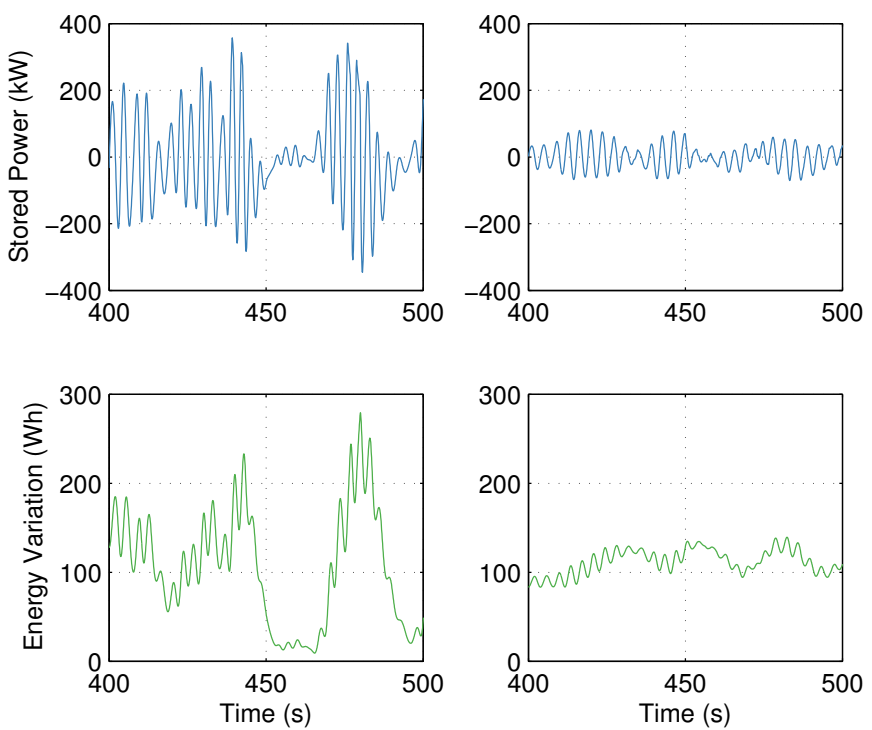

Fig. 6. Smoothing of Wave Energy Converter power production: comparison between a decentralized control and a centralized control that both satisfy the same flicker constraint

If we want to limit the noise perceived by the central ear by installing anti-noise panels around each speaker, like in the case (a), we can see that the pollution for each speaker of the crowed is also limited. Similarly, with a decentralized control of the Energy Storage Systems, the perceived pollution around the units is reduced.

If we install anti-noise panels exclusively in the direction of the ear, like in the case (b), we can see that the surface needed is less important than for (a), but the pollution perceived by each speaker is more important than for (a). Similarly, with a centralized control of the Energy Storage Systems, the perceived pollution around the units is not reduced, but the effect for the grid is the same with less storage.

\section{Sizing to Minimize the Life CyCle Cost}

\section{A. Considering Aging Model Uncertainty}

In order to predict the Life Cycle Cost, we must take into account the number of replacements needed during the period of use of the Wave Energy Farm (here, 20 years). But the aging models are not sufficiently accurate

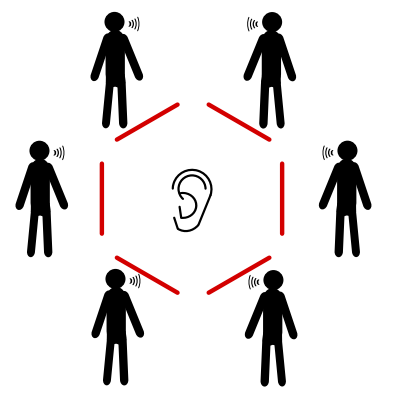

(b)

Fig. 7. Comparison with audible noise: a crowd makes noise and we want to install anti-noise panels to limit the noise perceived by the central listener: the case (a) corresponds to a decentralized smoothing: each speaker is surrounded by anti-noise panels, the case (b) corresponds to a centralized decision to install anti-noise panels exclusively towards the ear.

to make precise prediction about replacement needs. That is why we want to take into account the uncertainty concerning the aging model and hypotheses that have impact on aging, such as a constant ambient temperature.

It is usual during a model fitting to have experiments that differ from model within a factor 2 , and it is not rare to find a factor 3. That is why we will consider now the expected value of the number of replacement $\mathbf{E}\left(N_{\text {replace }}\right)$ with a multiplicative factor $e^{x}$ that follows a normal distribution:

$$
\mathbf{E}\left(N_{\text {replace }}\right)=\int_{-\infty}^{+\infty} \phi(x)\left\lfloor\int_{0}^{\Delta t} e^{x} \frac{\mathrm{d} S o A}{\mathrm{~d} t} \mathrm{~d} t\right\rfloor \mathrm{d} x
$$

with $\lfloor x\rfloor$, the floor function, that is the largest integer not greater than $\mathrm{x}, \phi(x)$, a probability density function of a normal distribution whose mean value is 0 (there is the same chance to underestimate or to overestimate the lifetime) and whose standard deviation is $\sigma=\ln (2)$, corresponding to a typical error factor of 2 (the lifetime prediction is two time shorter or longer than the real lifetime). Fig. 8 illustrates this hypothesis.

Fig. 8 shows the number of replacement as a function of the lifetime. The different areas represent different probabilities to have a number of replacement. This is close to reliability or decision risk approaches. For a lifetime prediction of 20,40 and 60 years, we can see the probability to have $0,1,2$ or 3 replacements.

We can notice that Fig. 8 does not depend on the aging model or even the problem, but only on the chosen 


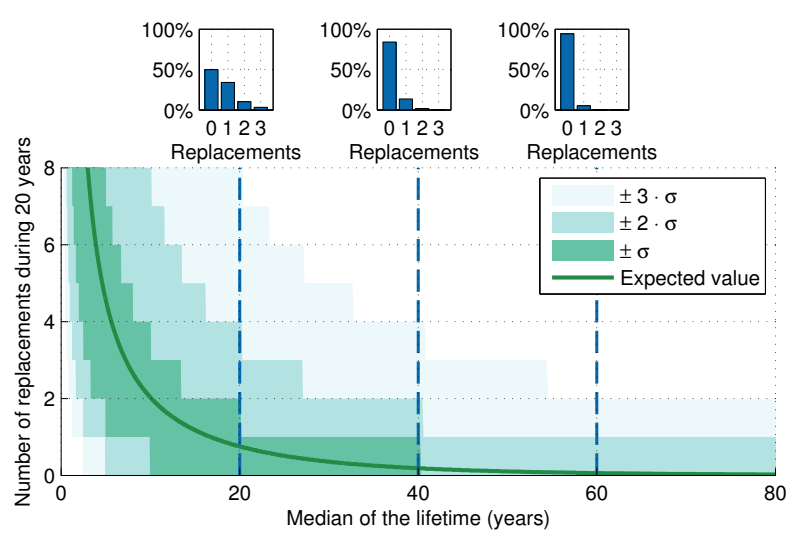

Fig. 8. Stochastic aging model: replacement as a function of median lifetime. For 20, 40 and 60 years, the probabilities to have $0,1,2$ or 3 replacements are shown.

distribution to represent the aging uncertainty.

\section{B. Life Cycle Cost Analysis}

The purpose of this model is to determine the sizing that minimizes the lifetime cost expected value $\mathbf{E}\left(C_{\text {life }}\right)$; this cost takes into account the price of losses using a feed-in tariff set at $c_{\text {Feed-in }}=0.15 € / \mathrm{kWh}$, with the initial investment costing $c_{\text {Energy }}=15 \mathrm{k} € / \mathrm{kWh}$ for the supercapacitors. The replacement cost considers just the price of the new storage system. So, this model does not take into account either the intervention cost or production losses during failure, both of which can be considerable in an offshore system.

The cost expected value is therefore computed with the following formula:

$$
\begin{aligned}
\mathbf{E}\left(C_{\text {life }}\right)= & c_{\text {Energy }} E_{\text {Rated }} \\
& +c_{\text {Energy }} \mathbf{E}\left(N_{\text {replace }}\right) E_{\text {Rated }} \\
& +c_{\text {Feed-in }} \overline{P_{\text {loss }}} \Delta t
\end{aligned}
$$

where $E_{\text {Rated }}$ is the rated capacity of the individual $\mathrm{ESS}, \Delta t$ is the lifetime of the DWEC system, set at 20 years, $\mathbf{E}\left(N_{\text {replace }}\right)$ the expected value of the number of replacements, defined in section III-A, and $\overline{P_{\text {loss }}}$ the average power losses in the ESS. Fig. 2 illustrates this Life Cycle Cost Analysis. One storage system is assigned to each of the 19 wave energy converters considered in this study.

We will compare the Life Cycle Cost of the individual storage system in both cases (centralized or decentralized control). We can see in Fig. 6 that this would also have an impact on the losses in the submarine cables of the farm, but it is considered here as negligible. The power transported by the main cable between the farm and the point of connection is almost the same in both cases, so it will not change the losses in this cable between this two cases.

\section{Results}

The expected cost value as a function of rated energy for both controls is shown in Figure 9 and Table II lists selected characteristics of the two optimal solutions corresponding to the two control types.
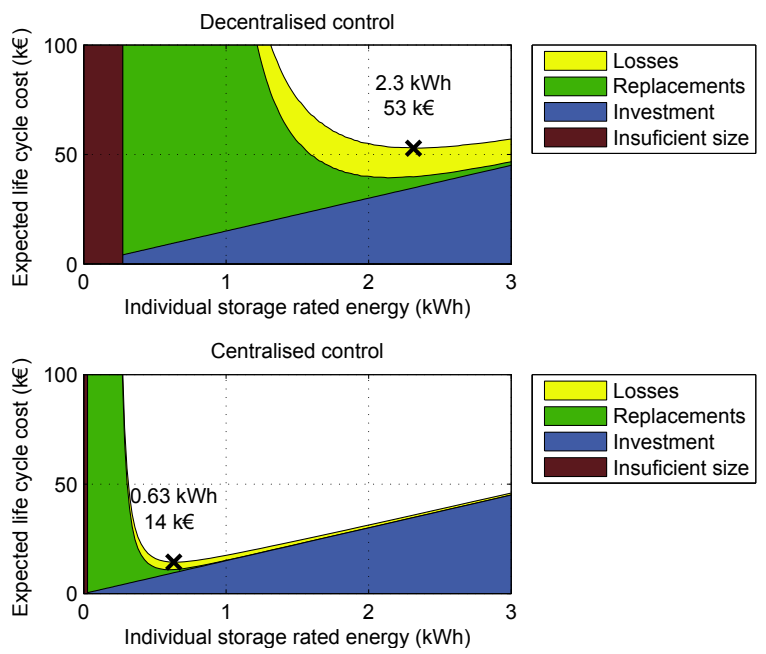

Fig. 9. Expected life cycle cost vs. individual energy capacity with the summation of the investment cost, the replacement expected cost and the losses cost.

We can see in Fig. 9 that the choice for the capacity of the storage systems is overall a trade-off between investment and replacements : losses have impact on the total cost, but have small impact on the capacity choice. The ratio between the two life cycle costs is very important (3.8), close from the expected $\sqrt{N}$ factor (4.4).

TABLE II. COMPARISON OF THE TWO OPTIMUMS (AMBIENT TEMPERATURE: $25^{\circ} \mathrm{C}$ )

\begin{tabular}{|c|c|c|}
\hline & Decentralized & Centralized \\
\hline$E_{\text {rated }}$ & $2.3 \mathrm{kWh}$ & $0.63 \mathrm{kWh}$ \\
\hline $\mathbf{E}\left(C_{\text {life }}\right)$ & $53 \mathrm{k} €$ & $14 \mathrm{k} €$ \\
\hline Weight & $1000 \mathrm{~kg}$ & $270 \mathrm{~kg}$ \\
\hline Volume & $2.2 \mathrm{~m}^{3}$ & $0.60 \mathrm{~m}^{3}$ \\
\hline Round trip efficiency & $98 \%$ & $98 \%$ \\
\hline Cell max. voltage & $2.23 \mathrm{~V}$ & $1.83 \mathrm{~V}$ \\
\hline Cell min. voltage & $1.93 \mathrm{~V}$ & $1.75 \mathrm{~V}$ \\
\hline Expected lifetime $($ median $)$ & 48 years & 43 years \\
\hline$p\left(N_{\text {replace }}=0\right)$ & $89 \%$ & $87 \%$ \\
\hline$p\left(N_{\text {replace }}=1\right)$ & $9.3 \%$ & $11 \%$ \\
\hline$p\left(N_{\text {replace }}=2\right)$ & $1.0 \%$ & $1.4 \%$ \\
\hline
\end{tabular}

Table II lists, among other things, the round trip efficiency [21], the probability that no replacement is necessary during the period of use $\left(p\left(N_{\text {replace }}=0\right)\right)$ and the probability that, respectively one or two replacements are necessary $\left(p\left(N_{\text {replace }}=1\right)\right.$ and $\left.p\left(N_{\text {replace }}=2\right)\right)$.

The two optimums solutions have similar efficiency and lifetime expectancy according to the Table II. We can 
notice that in order to limit the aging speed, the voltage range (from 1.93 to $2.23 \mathrm{~V}$ for the centralized control and from 1.75 to $1.83 \mathrm{~V}$ for the decentralized control) is considerably reduce compared to the rated voltage for this supercapacitor technology $(2.7 \mathrm{~V})$. The range of the State-of-Energy used is also relatively small, that justifies the electrical simplified model.

Clearly, the optimum solutions correspond to cases where the probability of replacements is small (around $10 \%$ ). This reduces the effect on the cost of the intervention and the losses during failures, that have been neglected here, even if they can be very important.

The expected value of the impact on the cost of energy $\mathbf{E}\left(I_{\text {Energy }}\right)$ can be formulated thanks the formula:

$$
\mathbf{E}\left(I_{\text {Energy }}\right)=\frac{\mathbf{E}\left(C_{\text {life }}\right)}{\overline{P_{\text {Prod }}} \Delta t}
$$

Thanks to the centralized control, the impact of the ESS on the energy cost changes from $2.41 €$ per MWh to $0.61 €$ per MWh.

\section{CONCLUSION}

The objective of this study was to determine the economic benefit which could be gained from centralizing the management of Energy Storage Systems. To help make this determination, electrical, thermal, aging and cost models have all been introduced. The life cycle cost analysis proposed herein has considered investment, replacements and losses.

Clearly, the centralized control need a much smaller energy storage system, but with more power fluctuations at the output of each devices. So the losses in the inverter and the farm cables are more important in this case. This effect is not taken into account in this study, but future study should investigate the effect on the life cycle cost of these elements.

The purpose of this sizing exercise has been to minimize life cycle costs. The final life cycle cost of roughly $14 \mathrm{k} €$ per unit for a centralized control seems to be acceptable and represents an impact on energy costs of around $0.61 €$ per MWh produced. This is negligible compared to a typical feed-in tariff for wave energy, for example 150 per MWh in France.

The aggregation effect significantly reduces the need of a storage to limit total power fluctuations. The case study here concerns power quality. However, similar methods could be used to demonstrate the importance of coordinating the energy storage systems connected into the grid for frequency regulation or productionconsumption balance.
This study is part of a more general design analysis of a complete electric conversion chain that takes lifetime into account [22][23]. In the case of DWEC, other more efficient control strategies are available [24], with more stringent power fluctuation. The influence of such control strategies for the energy recovery should be considered in future research on this topic.

\section{ACKNOWLEDGMENTS}

This work has been supported by the French National Research Agency (ANR) within the project QUALIPHE (power quality and grid integration of direct wave energy converters), which is part of the PROGELEC program.

\section{REFERENCES}

[1] A. J. Nambiar, A. E. Kiprakis, and A. R. Wallace, "Quantification of voltage fluctuations caused by a wave farm connected to weak, rural electricity networks," in International Conference on Harmonics and Quality of Power (ICHQP), Bergamo, Italy, Sep. 2010, pp. 1-8.

[2] F. Sharkey, J. MacEnri, E. Bannon, M. Conlon, and K. Gaughan, "Resource-induced voltage flicker for wave energy converters - assessment tools," IET Renewable Power Generation, vol. 7, no. 6, pp. 623-630, Nov. 2013.

[3] A. Blavette, D. L. O'Sullivan, R. Alcorn, T. W. Lewis, and M. G. Egan, "Impact of a Medium-Size Wave Farm on Grids of Different Strength Levels," Power Systems, IEEE Transactions on, vol. 29, no. 2, pp. 917-923, Mar. 2014.

[4] D. B. Murray, J. G. Hayes, D. L. O’Sullivan, and M. G. Egan, "Supercapacitor testing for power smoothing in a variable speed offshore Wave Energy Converter," Oceanic Engineering, IEEE Journal of, vol. 37, no. 2, pp. 301-308, 2012.

[5] T. Yoshida, M. Sanada, S. Morimoto, and Y. Inoue, "Study of flywheel energy storage system for power leveling of wave power generation system," in Electrical Machines and Systems (ICEMS), International conference on, Sapporo, Japan, Oct. 2012, pp. 1-5.

[6] Z. Nie, X. Xiao, Q. Kang, R. Aggarwal, H. Zhang, and W. Yuan, "SMES-Battery Energy Storage System for Conditioning Outputs From Direct Drive Linear Wave Energy Converters," Applied Superconductivity, IEEE Transactions on, vol. 23, no. 3, pp. 1-5, Jun. 2013.

[7] P. Haessig, B. Multon, H. Ben Ahmed, S. Lascaud, and L. Jamy, "Aging-aware NaS battery model in a stochastic windstorage simulation framework," in PowerTech, IEEE, Grenoble, 2013.

[8] R. Le Goff Latimier, T. Kovaltchouk, H. Ben Ahmed, and B. Multon, "Preliminary Sizing of a Collaborative System : Photovoltaic Power Plant and Electric Vehicle Fleet," in Ecological Vehicles and Renewable Energies (EVER), Monaco, 2014.

[9] T. Kovaltchouk, B. Multon, H. Ben Ahmed, J. Aubry, and P. Venet, "Enhanced aging model for supercapacitors taking into account power cycling: Application to the sizing of an Energy Storage System in a Direct Wave Energy Converter," in Ecological Vehicles and Renewable Energies (EVER), MonteCarlo, Monaco, Mar. 2014, pp. 1-10. 
[10] F. Baccino, F. Conte, S. Grillo, S. Massucco, and F. Silvestro, "An Optimal Model-Based Control Technique to Improve Wind Farm Participation to Frequency Regulation," Sustainable Energy, IEEE Transactions on, vol. PP, no. 99, pp. 1-11, 2014.

[11] A. D. Hansen, P. Sø rensen, F. Iov, and F. Blaabjerg, "Centralised power control of wind farm with doubly fed induction generators," Renewable Energy, vol. 31, no. 7, pp. 935-951, Jun. 2006.

[12] G. Bacelli, P. Balitsky, and J. V. Ringwood, "Coordinated Control of Arrays of Wave Energy Devices Benefits Over Independent Control," Sustainable Energy, IEEE Transactions on, vol. 4, no. 4, pp. 1091-1099, 2013.

[13] T. Kovaltchouk, K. Audoux, S. Rouland, J. Aubry, H. Ben Ahmed, and B. Multon, "Lissage dune production houlogénérée: gestion et dimensionnement dun système de stockage par supercondensateurs sous contrainte de flicker," in Symposium de Génie électrique, Cachan, France, Jul. 2014, pp. 1-9.

[14] IEC 61000-4-15, "Electromagnetic compatibility (EMC) - Part 4: Testing and measurement techniques - Section 15: Flickermeter - Functional and design specifications," 2003.

[15] E. F. Fuchs and M. A. S. Masoum, Power Quality in Power Systems and Electrical Machines. Academic Press, 2011.

[16] P. Jourdan, "Flickermeter Simulator," 2009. [Online]. Available: http://www.mathworks.fr/matlabcentral/ fileexchange/24423-flickermeter-simulator

[17] IEC 61400-21, "Wind turbine generator systems - Measurement and assessment of power quality characteristics of grid connected wind turbines," 2001.

[18] République Française, "Arrêté of 23 April 2008 on the technical design and operation for the connection of a power generation facility to a public electricity network of distribution in low or medium voltage (in french)," JORF, vol. 98, 2011.

[19] Maxwell Technologies, "Datasheet K2 Series Ultracapacitors," pp. 1-4, 2007.

[20] L. Johannesson, N. Murgovski, S. Ebbesen, B. Egardt, E. Gelso, and J. Hellgren, "Including a Battery State of Health model in the HEV component sizing and optimal control problem," in 7th IFAC Symposium on Advances in Automotive Control, 2013, pp. 398-403.

[21] B. Multon, J. Aubry, P. Haessig, and H. Ben Ahmed, "Systèmes de stockage d'énergie électrique," Techniques de l'ingénieur Nouvelles technologies, énergies renouvelables et stockage, vol. base docum, no. be8100, pp. 1-30, Apr. 2013.

[22] J. Aubry, H. Ben Ahmed, and B. Multon, "Sizing Optimization Methodology of a Surface Permanent Magnet MachineConverter System over a Torque-Speed Operating Profile : Application to a Wave Energy Converter,' Industrial Electronics, IEEE Transactions on, vol. 59, no. 5, pp. 2116,2125, 2012.

[23] T. Kovaltchouk, J. Aubry, B. Multon, and H. Ben Ahmed, "Influence of IGBT current rating on the thermal cycling lifetime of a power electronic active rectifier in a direct wave energy converter," in Power Electronics and Applications (EPE), Lille, 2013, pp. 1-10.

[24] T. Kovaltchouk, B. Multon, H. Ben Ahmed, F. Rongère, A. Glumineau, and J. Aubry, "Influence of control strategy on the global efficiency of a Direct Wave Energy Converter with electric Power Take-Off," in Ecological Vehicles and Renewable Energies (EVER), Monte-Carlo, Monaco, Mar. 2013, pp. $1-10$. 